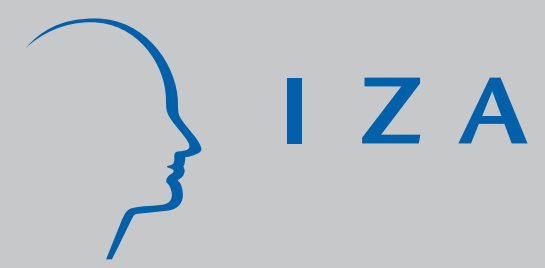

IZA DP No. 8040

Modelling Exposure to Risk of Experiencing Discrimination in the Context of Endogenous Ethnic Identification

Boyd Hunter

Monica Howlett

Nicholas Biddle

March 2014 


\title{
Modelling Exposure to Risk of Experiencing Discrimination in the Context of Endogenous Ethnic Identification
}

\author{
Boyd Hunter \\ CAEPR, Australian National University \\ and IZA \\ Monica Howlett \\ CAEPR, Australian National University \\ Nicholas Biddle \\ CAEPR, Australian National University
}

Discussion Paper No. 8040
March 2014

IZA

P.O. Box 7240

53072 Bonn

Germany

Phone: +49-228-3894-0

Fax: +49-228-3894-180

E-mail: iza@iza.org

Any opinions expressed here are those of the author(s) and not those of IZA. Research published in this series may include views on policy, but the institute itself takes no institutional policy positions. The IZA research network is committed to the IZA Guiding Principles of Research Integrity.

The Institute for the Study of Labor (IZA) in Bonn is a local and virtual international research center and a place of communication between science, politics and business. IZA is an independent nonprofit organization supported by Deutsche Post Foundation. The center is associated with the University of Bonn and offers a stimulating research environment through its international network, workshops and conferences, data service, project support, research visits and doctoral program. IZA engages in (i) original and internationally competitive research in all fields of labor economics, (ii) development of policy concepts, and (iii) dissemination of research results and concepts to the interested public.

IZA Discussion Papers often represent preliminary work and are circulated to encourage discussion. Citation of such a paper should account for its provisional character. A revised version may be available directly from the author. 


\title{
ABSTRACT
}

\section{Modelling Exposure to Risk of Experiencing Discrimination in the Context of Endogenous Ethnic Identification*}

\begin{abstract}
Gneezy et al. (2012) uses attribution theory from the psychology literature to argue that when the object of discrimination is a matter of choice (e.g. sexual orientation), observed discrimination may motivated by animus, which exacerbates or intensifies the emotional response to the object of discrimination. This paper builds on this insight based on the understanding that ethnicity is largely a social construct where individuals can often choose to identify with an ethnic group that may be the object of discrimination. A theoretical model is constructed that predicts that the choice to identify interacts with the observability of ethnicity, and the exposure to situations where there is a risk of discrimination, to produce a non-linear relationship with reported episodes of discrimination. Evidence from the 2008 National Aboriginal and Torres Strait Islanders Social Survey (NATSISS) is presented that is consistent with the predictions of this theory.
\end{abstract}

JEL Classification: J15, J71, Z13

Keywords: discrimination, racial bias, identity, social networks

Corresponding author:

Boyd Hunter

Centre for Aboriginal Economic Policy Research

College of Arts and Social Sciences

Research School of Social Sciences

The Australian National University

Canberra ACT 0200

Australia

E-mail: boyd.hunter@anu.edu.au

\footnotetext{
* We would like to thank Joan Rodgers and attendants at the 2012 Australian Labour Market Research workshop held in Perth for their helpful comments and suggestions. Any remaining errors are our own.
} 


\section{Introduction}

Labour market discrimination is said to occur when employers treat workers or potential employees in different ways based on non-labour characteristics. Economists tend to define discrimination in rather abstract terms as 'the valuation in the market place of personal characteristics of the worker that are unrelated to worker productivity' (Arrow 1973). Personal characteristics that may be the subject of discrimination can include: sex, race, age, national origin, religion, disability or sexual preference. Discrimination is a cause of labour market failure and a source of inequity in the distribution of income and wealth and it is usually subject to government intervention through regulation and legislation. Discriminatory treatment of minority groups can lead to lower wages and reduced employment opportunities, including less training and fewer promotions.

Existing economic theories of explicit discrimination focus on explaining the behaviour of discriminators either through tastes or signalling. The theory of Gary Becker, that is firmly grounded in neoclassical economics, focuses on the preferences of employers who are said to have a 'taste for discrimination' (1971). Such employers are willing to pay a price to avoid contact with other groups and, in the context of Indigenous peoples, this can be understood as a form of racial prejudice. Becker's theory, and associated expositions, are useful in highlighting that employers who discriminate against productive workers do so potentially at an economic cost to themselves and, in some sense, it is not 'economically rational' (Arrow 1998).

Another relevant theory based on imperfect information involves statistical discrimination whereby employers use ethnicity and other non-productivity related characteristics as a signal of true worker productivity, which is costly and difficult to observe directly; under such conditions employers can maximise profits by focussing on the average characteristics of the group being discriminated against (Phelps 1972, Arrow 1973 both provide a non-Walrusian general equilibrium analysis of discrimination).

Standard economic theories can possibly assist policy makers to understand some aspects of discrimination, however it is important to understand what happens to the person being discriminated against rather than solely focussing on the behaviour of the discriminator. The choices of the target of discrimination can interact with the preferences of the discriminator and could exacerbate the effect of discrimination. This paper focuses on modelling selfreported instances of discrimination not because those who are discriminated against are somehow at fault, but rather because the response to perceived discrimination is important in their own right (e.g., with respect to labour supply decisions, Goldsmith et al. 2004). ${ }^{1}$ Also many surveys collect information on self-report information on discrimination and hence theoretical propositions can be tested against such data.

1. Furthermore, it is difficult to enact laws that adequately address the discriminatory behaviour of employers

(De Plevitz 2000), and therefore addressing the policy might find it more productive to focus on the person being discriminated against. 
Australia has several reliable large scale omnibus social surveys that are ideal for testing propositions about discrimination using self-report data. Borland and Hunter (2000) demonstrate that Indigenous peoples in English-speaking settler societies appear to experience extreme labour market disadvantage relative to other citizens. This is especially the case amongst Australia's Aboriginal and Torres Strait Islander peoples (also see Hunter and Daly 2013). Hunter and Gray (2012: 16, Fig. 3) describe the prevalence of self-reported discrimination by labour force status and come to the conclusion that far too many Indigenous Australians experience some form of discrimination irrespective of their labour force status. Using data from the 2008 National Aboriginal and Torres Strait Islander Social Survey (NATSISS), they found that around half of Indigenous unemployed report having experienced discrimination in the last year, while approximately 30 per cent of other Indigenous males and females report discrimination. A potential, though little understood, driver for the higher rate of discrimination is that the unemployed are exposed to more potential discriminators as the process of job search brings them into contact with prospective employers (Biddle et al 2013). The high level of self-reported discrimination among Indigenous Australians is consistent with overall perceptions of the Australian public. The Reconciliation Barometer, conducted by Auspoll (2012) for Reconciliation Australia showed that 23 per cent of Australians report that the level of prejudice Australians hold towards Indigenous people is very high, with a further 53 per cent reporting that prejudice is fairly high. ${ }^{2}$ Furthermore, 82 per cent of respondents felt that discrimination was either a very important or fairly important factor in 'creating disadvantage amongst some Indigenous people.' Given the substantial experience of discrimination by Indigenous Australians, the NATSISS data may provide sufficient statistical power to test the theoretical propositions generated in this paper.

The next section provides some tentative steps towards a theoretical model of the risk of exposure to discrimination and reporting of discrimination. One of the main contributions of this paper is to endogenise the choice individuals' make to publicly identify with the ethnic group that may exposed to interactions with potential discriminators. Given that ethnicity may not be immediately obvious to casual observers, the choice to identify as a particular ethnicity will have important implications for understanding who is likely to experience and report discrimination.

2. Only a small minority of the general population reported that they themselves had negative attitudes towards the Indigenous population, Around 14 per cent of the general community either disagreed or strongly disagreed that 'I would feel fine if I had a child who decided to marry an Indigenous person.' Only 10 per cent agreed or strongly agreed that non-Indigenous Australians are superior to Indigenous Australians. Finally, 9 per cent of respondents reported that they wanted to have no contact with Indigenous people. But, only a small minority of the community reported favourable attitudes to Indigenous Australians in domains related to the labour market and education. That is, only 20 per cent of the general community thought that Indigenous Australians were hard working compared to 71 per cent of who thought Australians in general are. Furthermore, only 15 per cent thought Indigenous Australians were disciplined compared to 41 per cent for Australians in general. 


\section{Modelling Discrimination and the Exposure to Discrimination}

Discrimination is likely to be a relatively rare event (at least on average across the population) that occurs episodically. Empirically, such phenomena are sometimes modelled using a count data model using the Poisson, Negative Binomial or similar distributions. Such distributions are necessary to account for the fact that a small number of discrete occurrences mean that there are not enough observations to justify the assumption of a Normal distribution in the observed data. Count data is typically measured in non-negative integers to capture some non-divisible event or outcome. Given that a discriminatory event either occurs or does not occur, it is a non-divisible outcome that can be theoretically be 'counted'. In practice, a discrete event is not always directly observed, and a person may come to the conclusion they have been discriminated against on the basis of a series of negative social interaction. Of course the conclusion of an individual may not accord with the interpretation of the person doing the alleged discrimination, however it is the authors' contention that the belief that one has been discriminated against is worthy of study irrespective of the objective 'truth' of the claim (though the 'truth' of the claim is also worthy of study in and of itself).

Another notable feature of count data models is that they often explicitly include a proxy for exposure (to risk). While no data currently exists on the number of discriminatory events, we maintain that it is useful to think of discrimination arising as a result of exposure to a relatively small number of potential discriminatory events that have a cumulative effect on an individual's labour supply preferences and labour market behaviour. The greater the number of discriminatory events, the larger the likely impact on labour supply and other outcomes. While it may not be possible to formally model discrimination as a count data model, we would argue that there is a strong case to conceptualise the effect of discrimination being associated with the number, and possibly the type, of discriminatory events. An example of the latter is labour market discrimination, which is likely to have a relatively strong correlation with labour market outcomes. However, discrimination in other domains of life may also provide information to job seekers about the general level of prejudice they may encounter when looking for a job.

This paper relies on self-reported discrimination because, as pointed out above, it is difficult to directly observe employer discrimination and the employer may be unaware that they are discriminating. Hence, it is easier to collect information from survey respondents. Even if some credible 'objective' measure of discriminatory events existed, a strong case could be made that it is entirely appropriate to use self-reported discrimination as it is the subjective evaluation of the existence of discrimination that affect an individual's decision to supply labour.

The subjective nature of such data raises the possibility of feedback into the psychological processes whereby a person decides to report a subsequent interaction as being discriminatory. For example a person may use discrimination as a way of shifting the blame for some undesirable event out of their control (Crocker and Major 1989); conversely an individual may deny discrimination occurred to avoid confronting a difficult problem (Crosby 1984). The importance of such feedback is that separate effects can compound and lead to a multiplicative interaction between factors. However, psychological feedback is only 
one possibility and there are alternative explanations of potential non-linearities of factors that may drive discriminatory events that we will return to later.

First, we need to understand the factors that might increase the risk of exposure of reporting discrimination. Such factors can be put into two categories: external factors and internal factors associated with exposure to risk of experiencing discrimination. In broad terms external factors are observable by others whereas internal factors are not observable by others.

\section{$2.1 \quad$ Visibility}

The basic factor driving racial discrimination is whether race is observable by outsiders. Some of the early anthropologists and archaeologists spent a great deal of time identifying the physical characteristics of Aboriginal peoples (sometimes called Anthropometry). ${ }^{3}$ We do not deny the absolute centrality of self-identification as a means for counting the Indigenous population or for access to government services. But, while it is relatively rare for people to talk openly about the typical physiognomy of various types of Indigenous people in contemporary Australia, there is still a reasonably clear image of a 'full blood' Aboriginal, probably based on, if not 'informed' by, a more or less constant stream of media images of Indigenous footballers, artists, and films (as well as visual media reports from 'emergency responses' and 'interventions'). People who have such physical characteristics will be marked for discrimination by the potential discriminator.

It is reasonable to assume that the observability of indigeneity varies according to the extent that a person conforms with a physical stereotype of what an Aboriginal or Torres Strait Islander looks like. Consequently, observability of indigeneity or what we call visibility should be conceptualised as a continuous variable that varies between 0 and 1, with 0 being totally unobservable and 1 being unambiguously identified as Indigenous by an external observer.

One explicit feature of this hypothetical index of visibility that we denote as $\mathrm{V}$ is that the relationship with genetics is not always straightforward or necessary. Someone with only Indigenous ancestry may not completely conform to the archetypal physiology and someone with a fraction of their ancestors being Aboriginal and Torres Strait Islanders may conform completely to the stereotype. Another feature of the index could be that there is probably considerable variation in the information about what the archetypal physiology is between individuals. Consequently, different individuals may assess the conformity with a stereotype differently. Indeed, even one individual may be rather uncertain about $\mathrm{V}$ and rank the same individual differently in different situations. One way of characterising such variation is to

3. Observable craniofacial differences that relevant anthropologists studied included: head shape breadth of nasal aperture, nasal root height, sagittal crest appearance, jaw thickness, brow ridge size and forehead slope. Typologies based on observable differences were not always consistent and many modern scholars are suspicious of the observations of earlier studies which also tended to be associated with other spurious individual characteristics (Gould 1981). 
say that the index is measured with considerable error, but the index will always be bound between 0 and 1 .

In contrast to early anthropometric studies, we are not claiming that this index is in any sense objective. Rather it can be thought of as the proportion of the rest of the population who identify a given person as having Indigenous ancestry. Of course this raises the prospect that some people are incorrectly identified as having Indigenous ancestry; however, we focus on the overall identification as potential discriminators are likely to discriminate on their beliefs irrespective of whether those beliefs are grounded in fact.

Clearly, V may be difficult (or impossible) to measure in survey contexts but it may be measured in psychometric testing. If one abstracts from the difficulty in measuring the $\mathrm{V}$, it is our assumption that any model of experiencing and reporting discrimination will be an increasing function of this index. The more the racial characteristics are observable, the more likely that potential discriminators can act on their prejudice (or have a taste for discrimination), for employers (and other authority figures) to statistically discriminate against the person 'observed', or for implicit views to translate to behaviour.

The hypothesis that $\mathrm{V}$ is an important driver of discriminatory experience is consistent with the international literature. For example, there are several Canadian-based studies on the effect of visibility, with results suggesting that visible minorities (especially blacks and Asian groups) are more likely to perceive discrimination than 'non-visible' (white) minorities (Dion 1989, Dion and Kawakami 1996, Banerjee 2008).

\subsection{Exposure}

There are several other external factors associated with exposure to situations that involve discrimination, although they all rely, to varying degrees, on either the observability of Indigeneity or the discoverability of Indigenous status through social interactions and contexts. One of the relevant factors for any estimate of exposure to discrimination is the likelihood that an Indigenous person randomly meets a potential discriminator in their daily interactions in the local area or their job search.

One simplifying assumption for this paper is that any non-Indigenous person could be a potential discriminator. This assumption implicitly presupposes that Indigenous people do not discriminate against other Indigenous people, which may not be justified in all circumstances. However in the context of a labour market study, the small number of Indigenous employers means that we can effectively discount the importance of Indigenous-to-Indigenous discrimination - at least in the Australian context. While we expect a lower (but non-zero) level of discrimination from an Indigenous person, it is relatively straightforward to extend a theoretical model to explicitly take this into account.

The limited research to date suggests that while discrimination experienced by Indigenous people is predominately perpetrated by non-Indigenous people. However, it is also clear that 'lateral violence' (i.e. racism perpetrated by Indigenous people against other Indigenous people) also occurs (Paradies and Cunningham 2009). Even if we discount the possibility of 
Indigenous-to-Indigenous discrimination in the labour market, it is difficult to entirely discount the possibility for other forms of discrimination.

In geographic studies, the exposure (E) of an Indigenous person (IND) to a random NonIndigenous person (NI) in an area is calculated as (following formulation adapted from Galster and Keeney 1988):

$$
E=\left(\frac{1}{I N D}\right) \sum_{i=1}^{n}\left(I N D_{i} * \frac{N I_{i}}{\left(N I_{i}+I N D_{i}\right)}\right)
$$

$\mathrm{E}$ is estimated by summing the numbers of the respective racial categories over the $\mathrm{n}$ subareas. It can be interpreted as the probability of an IND meeting a NI at random given a particular level of spatial segregation of respective racial groups. This measure of exposure to potential discriminators would be a suitable explanatory factor for any model of general discrimination; it would also provide a valid explanatory variable for labour market discrimination to the extent that the local labour market is likely to be a microcosm of the local geographic context (with some modification if the data is available).

Another variable that broadly measures exposure, that is easier to estimate for most analysts, is the proportion of the local area who identify as Indigenous people (usually calculated using census data). The drawback of this measure of exposure to situations that may involve discrimination is that it effectively ignores the valuable information on the spatial distribution of Indigenous and Non-Indigenous persons.

Local geographic context provides one measure of exposure to potential discriminators, however social networks and communities are not necessarily bounded within particular areas (McMillan and Chavis 1986). Consequently, another measure of exposure to potential discriminators is the proportion of social contacts who are non-Indigenous. It is now relatively common to collect information on social capital in survey data including the ethnicity of social networks. While some social capital literature is motivated in terms of discrimination (facing individuals and groups), we should acknowledge that social capital does not only reflect on discriminatory structures and practices are reinforced within social networks (Woolcock 2001). Accordingly, social capital measures may be associated with alternative outcomes in that literature including generalised trust and the economic and social value of social networks. Notwithstanding, the social capital variables used in this study only pertain to the extent that they reflect contact with potential discriminators (non-Indigenous people). It is important to note that social capital based on the indigeneity of social networks can also be interpreted as publicly revealing one's Indigenous identity and hence may also be interpreted in terms of $\mathrm{V}$ rather than $\mathrm{E}$.

Another aspect of exposure to discrimination is where a person puts themselves in situations where they are more likely to encounter potential discriminators (non-randomly). In the context of labour supply, the process of active job search across a more diverse set of employers means that a person is increasing their own exposure to potential discriminators. 
Note that passively avoiding the process of applying for jobs is not an option for the unemployed persons who receive income support payments and are obliged to actively seek work. Recent research shows that other jobseekers are also exposed to more discrimination (Biddle et al. 2013).

The above discussion speculates about the possibility of non-linearities in the effect of exposure via psychological feedbacks. Another plausible rationale is that there are diminishing returns to discrimination for exposure and other measures of potential discriminators. When the group being discriminated against is small, and exposure to potential discriminators is high, employers may get large returns from discriminating. However, as one expands the pool of jobseekers that one is discriminating against by including people with less observable indigeneity, then the employers can run the risk that they eliminate excessive numbers of job applicants even though many may be sufficiently productive to add value to the enterprise's bottom line. If we emphasis diminishing returns to discrimination one might expect discrimination to be some quadratic function of exposure (i.e., a graph of discrimination would look like an 'inverted U' when measured against exposure).

Another possible source of non-linearity in the determinants of discrimination is that race based prejudice interacts with class-based attitudes to reinforce discriminatory behaviour, particularly in low socioeconomic status areas (Galster and Keeney 1988). Therefore given the disproportionate concentration of Indigenous people in low status areas, discrimination may be particularly high there, even though the exposure to potential discriminators may be relatively low. Consequently, even though increased exposure to potential discriminators will generally increase the experience and reporting of discrimination, the relationship between exposure and discrimination could be either linear or non-linear.

\subsection{Choice to identify with a group experiencing discrimination}

Internal psychological factors, that are not observable by others, can also be drivers of discriminatory behaviour and the reporting of discrimination. For example, both Becker (1971) and the statistical discrimination models of discrimination involve beliefs that are not possible for others to observe. Obviously, to the extent that employer preferences are driving discriminatory behaviour, it is crucial to understand the psychology of individual employers. That is, it is important to further unpack the motivation of such employers to understand the prevalence of discrimination and the factors driving that discrimination. Even statistical discrimination is based on the fact that employers have (non-observable) beliefs based on imperfect information about worker's true productivity.

A recent NBER paper by Gneezy et al. (2012) uses a series of field experiments to measure discrimination based on gender, age, sexual orientation and disability. The paper makes the important distinction between when the object of discrimination is uncontrollable (e.g. gender and race) and when the object of discrimination is, at least according to the discriminator, due to choice (e.g. sexual orientation). Where the object of discrimination is uncontrollable, the evidence suggests that statistical discrimination is the underlying reason for the disparate 
behaviour. On the other hand, when the object is due to choice, there is evidence to suggest observed discrimination is motivated by animus.

Gneezy et al. (2012) is motivated by the attribution theory from the psychology literature where individuals make attributions about the cause and controllability of an action or stigma, which lead to emotional reactions that affect the likelihood of helping or punishing behaviours. ${ }^{4}$ Heider (1958) showed that the decision maker takes into account others motives, cognitive processes, and situational constraints when attributing causal inference and perceiving social contexts. Another example is Greenberg and Frisch (1972) where assistance that is deliberately provided by helpers leads to more reciprocity than does accidental help. The most relevant aspect of the attribution literature is the finding that individuals are more prejudice towards those demonstrating behavioural conditions such as obesity (Rukavina and Li 2011), homosexuality (Haider-Markel and Joslyn 2008), or drug addiction that are perceived as controllable (Corrigan, Kuwabara and O'Shaughnessy 2009). In contrast, personal characteristics perceived to be outside the control of the individual, including physical attributes such as blindness or paraplegia, were more likely to elicit pity and help from others (Weiner, Perry and Magnusson 1988). The implicit behaviour that this pity engenders is, it should be noted, a gap in the literature.

The first reaction of readers might be to discount race as a physical characteristic that can be considered a choice. The paper explicitly recognises that indigeneity is not just a racial characteristic that is 'objectively' observable. Indigenous people, like other racial and ethnic groups, can choose to identify with their culture, ethnicity, and race. The later choice is in some sense constrained by the extent to which other people treat you as Indigenous or other racial and ethnic groups.

The philosopher Willard Van Orman Quine wrote that there is 'no entity without identity' (1981: 102). The quote resonates beyond the clever word play in that individuals need identity to exist and hence our interactions with social networks and our communities are crucial determinants of most people's behaviour.

For many Indigenous people, the act to identify as Indigenous is both a choice and a political act. The dramatic increase in the identification of Indigenous people in the Census data since at least 1971 (and quite rapidly over the last intercensal period) is evidence that people with Indigenous heritage are increasingly likely to be making that choice. In a sense this is a positive reflection on the long run changes in Australian society where the level of public stigma associated with Indigenous identification has abated over time (Hunter and Dungey

4. One potential limitation of Gneezy et al. (2012) is that it pays insufficient attention to the expanding psychological literature on implicit prejudice. 
2006). ${ }^{5}$ Another factor may be the more positive social relations embodied in the Prime Minister Kevin Rudd's 2008 Apology to Australia's Indigenous Peoples (see Hansard: http://parlinfo.aph.gov.au).

One way to measure choice would be to conceptualise it as the obverse of the index V (or more precisely $1-\mathrm{V}$ ). The rationale for this is that the extent to which one can be observed as Indigenous by the average citizen is the extent to which one does not have a choice as to whether a person identifies as Indigenous. That is, if a person does publicly identify as Indigenous, then $1-\mathrm{V}$ can be thought of as the 'involuntary choice' to identify as Indigenous. (from the point of view of the general non-Indigenous public). If one accepts that $\mathrm{V}$ is also associated with exposure to discriminatory situations and choice as to Indigenous status, then this has potential implications for the way in which it is introduced into the model.

Other factors (denoted as $\mathrm{O}$ in the following equations) may also drive the incidence of discrimination. Any factor that is associated with prejudice will tend to increase the number of expected instances of discrimination. Galster and Keeney's (1988) empirical model of prejudice includes both economic disparities and certain socio-demographic characteristics in the local area. They model prejudice as increasing directly with age of other residents, but as varying inversely with education and socioeconomic status. Economic inequalities enter their formulation separately because racial antagonisms could be intensified in areas where the racial group is more numerous and economically mobile than other citizens and hence are viewed as an economic threat.

\section{$2.4 \quad$ An overall model of discrimination}

From the above, Discrimination for an individual who does not publicly choose to identify as being Indigenous, (D), is a function of the index of observability or visibility (V), exposure to interactions with potential discriminators (E, that may include spatial segregation of races, situations where one is more likely to meet discriminators such as job search), the extent of 'choice' in identifying as Indigenous (1-V), and other relevant factors, O. Given that we are defining visibility and choice as being directly related, D reduces to a three-dimensional function:

$$
D=f\left(V, E, O \mid \operatorname{Ind}_{i}=1\right)
$$

As indicated to above, the function $\mathrm{f}$ is likely to follow a statistical distribution associated with count data models where the expected number of events is relatively small (e.g. the asymmetric Poisson distribution). However, if we are constrained to a sole indivisible event,

5. The substantial non-biological growth in the Indigenous population in census data can include a component due to increased (or decreased) propensity to identify as Indigenous and another component due to inter-marriage between in various sub-populations - in particular, an increased rate of identification arising from the resulting progeny from such marriages. Another factor that effects nonbiological growth is the change in both coverage of sub- populations (Guimond 1999) and the census editing procedures (Ross 1999). 
say the reporting of some discriminatory event in a recent period, then $f$ should be thought of as following a logistic or a similar distribution.

Given equation (2) broadly includes the major factors driving discriminatory behaviour, in abstract terms, the issue of how one combines the internal and external drivers of discrimination in the specification has important implications for modelling self-reported discrimination. We illustrate some of the relevant issues with simulations based on a plausible specifications that combine $\mathrm{E}, \mathrm{V}$ and $(1-\mathrm{V})$ in Figures 3. One way for $\mathrm{V}$ and $(1-\mathrm{V})$ to interact to generate non-linearity is to compound the effects other explanatory factors in a multiplicative fashion.

If $\mathrm{V}$ and $(1-\mathrm{V})$ interact multiplicatively with each other and $\mathrm{E}$ is interpreted as the probability that a person is exposed to potential discriminators, then the size of the compounded effect of $\mathrm{V}$ on discrimination will be weighted by this probability.

$$
D=g\left(V \times(1-V) \times E, O \mid \operatorname{Ind}_{i}=1\right)
$$

The first argument in brackets in equation (3), which is transformed by the function $g$ to predict reported discrimination (D), would look something like the simulations presented in Figure 1. There is no contribution to expected $\mathrm{D}$ when $\mathrm{E}$ is zero, irrespective of the extent of $\mathrm{V}$ and the choice implied by that $\mathrm{V}$; that is, no discrimination might be reported as there is no exposure to risk of discrimination (live in areas where residents are all Indigenous, have no social contacts with non-Indigenous citizens and individuals do not look for work etc.). Clearly that is a trivial case that involves Indigenous Australians living virtually in a 'bubble', which is impossible in the modern world. The other trivial cases when this argument in $\mathrm{f}^{\prime}$ always equals zero, is where either $\mathrm{V}$ or $(1-\mathrm{V})$ equals zero. The non-trivial cases however, are more interesting. The argument or term illustrated in Figure 1 is an increasing linear function of $\mathrm{E}$ but is non-linear in $\mathrm{V}$. The non-linearity is driven by the fact that the incremental discrimination from increasing visibility (from total invisibility) grows initially, but at a decreasing rate. This may occur because the effect of increasing $\mathrm{V}$ on $\mathrm{D}$ is counteracted by the effect of diminishing $(1-\mathrm{V})$ on $\mathrm{D}$. Hence one implication of this simulation is that $\mathrm{D}$ is driven simultaneously by both $\mathrm{V}$ and $(1-\mathrm{V})$, and that we would expect the highest reporting of discrimination among those who only half of the general population are visibly identified as Indigenous. As $\mathrm{V}$ increases beyond the maximum, then this argument in $g$ starts to fall at an accelerating rate. Given that other factors $(\mathrm{O})$ also enter the function $\mathrm{g}$, even though the argument illustrated in Figure 1 equals 0 , there is no assumption that the expected counts or probability of reported discrimination also equal 0 . Other factors are likely to lead to a non-zero count or probability for discrimination.

This prediction of non-linearity in $\mathrm{V}$ is one of the important contributions of this paper as it demonstrates why people whom all Australians would perceive to be Indigenous are not necessarily the group who will be the most likely to experience and report discrimination. Unfortunately, the difficulty in measuring $\mathrm{V}$, means that it is not possible to directly test this prediction at this stage. Also, in practice $\mathrm{V}$ is likely to be highly correlated with certain proxy measures for $\mathrm{E}$ in survey data, and hence the multivariate empirical analysis will look for 
non-linearities in various proxies for $\mathrm{E}$. These predictions for the relationship between discrimination and $\mathrm{E}$ could also be attributable to diminishing returns to discrimination as well as indirectly reflecting the inverted $U$ shape we argue should be expected for discrimination plotted against $\mathrm{V}$.

Figure 1. Hypothetical Simulations Based on Exposure (E) with Compounding Multiplicative Effect of Visibility (V) and Extent of Involuntary Choice in Indigenous Identification (1-V)

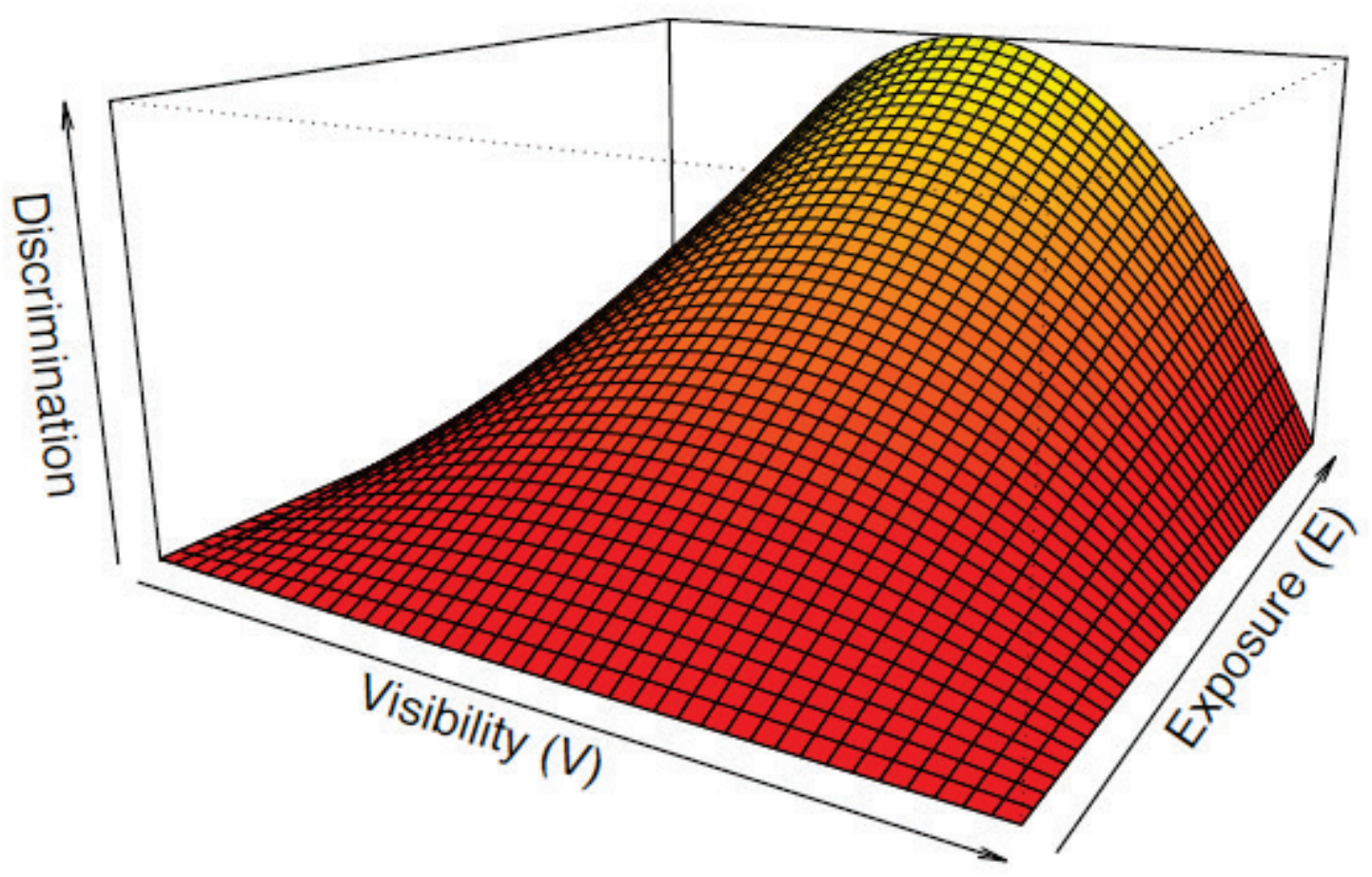

Note. The y-axis is one hypothetical argument for predicting $D$ in equation (3) defined as equal to $E^{*} V^{*}(1-V)$ where $\mathrm{c}=1$. Both $\mathrm{V}$ and $\mathrm{E}$ could be thought of as an index uniformly distributed between 0 and 1 . 
Figure 2. Contour plot for discrimination with different levels of exposure (E) and involuntary choice to identify as Indigenous modelled as (1-V)

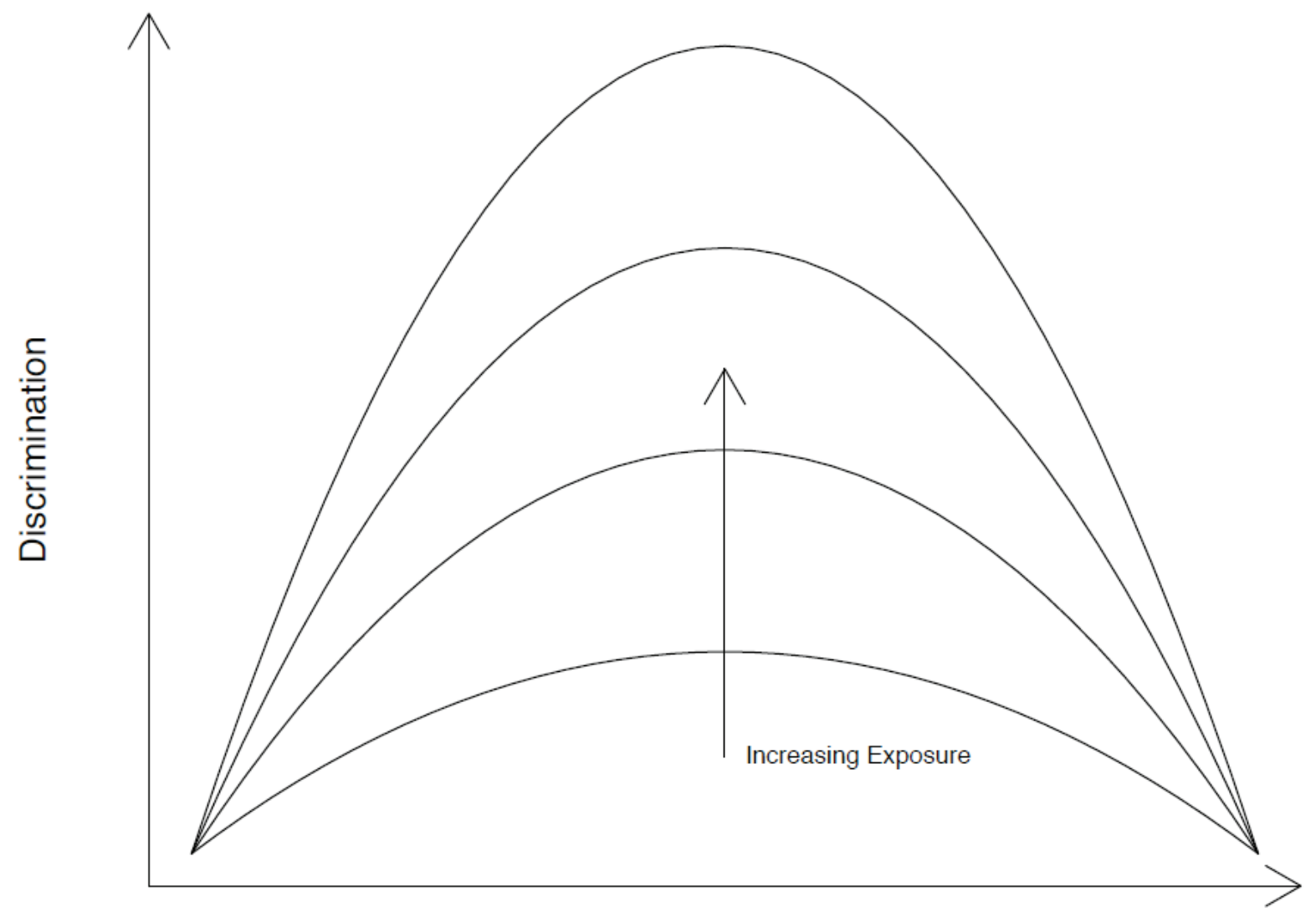

Visibility

The theoretical prediction about the hypothetical argument used in predicting discrimination (illustrated by the y-axis in Figure 1), will need adjustment when there are diminishing returns to discrimination associated with $\mathrm{E}$. In that case the self-reported discrimination would increase to a certain value when diminishing returns to the discriminator sets in (see e.g., the discussion in Galster and Keeney 1988). The diminishing returns in both V and $\mathrm{E}$ would mean that the reported discrimination, or rather the first term in equation (3), can probably be best represented as a rounded 'hill' (or a 'three dimensional inverted U').

Figure 2 demonstrates that discrimination is always increasing in $\mathrm{E}$ whatever the visibility or involuntary choice to identify as Indigenous.

The above analysis is implicitly based on the assumption that a person chooses not to publicly identify as Indigenous. We can generalise this model by allowing an individual to publicly identify as Indigenous in a certain number of circumstances. Of course, it may be difficult to publicly identify with a group when one is dealing One way to measure choice would be to conceptualise a third component $\mathrm{C}$, or voluntary choice to publicly identify as indigenous. If an individual chooses to publicly identify as Indigenous, then voluntary choice 
$\mathrm{C}$ would replace involuntary choice $(1-\mathrm{V})$ as a factor driving the experience of discrimination in equation 3. To the extent that a person does not voluntarily choose to identify as Indigenous means that involuntary choice has a role to play in predicting discrimination. In order to operationalise this insight let $\mathrm{c}$ denote the proportion of circumstances that an Indigenous people would choose to publicly identify as indigenous where $0 \leq c \leq 1$. In those c circumstances, this voluntary choice will compound the effect of being observed to be Indigenous. However, in the other (1-c) circumstances the effect of being observed to be Indigenous will be compounded by the involuntary choice (1-v). Therefore the model outlined in equation 3 could be generalised to explicitly take into account the role of voluntary choice in equation 4 below.

$$
\mathbf{D}=\mathbf{g}\{[\mathbf{c . v}+(\mathbf{1}-\mathbf{c}) \cdot \mathbf{v} \cdot(\mathbf{1}-\mathbf{v})], \mathrm{E}, \mathrm{O}\}
$$

Figure 3. Hypothetical Simulations Based on Interaction of Visibility (V) and Extent of voluntary Choice in Indigenous Identification (C)

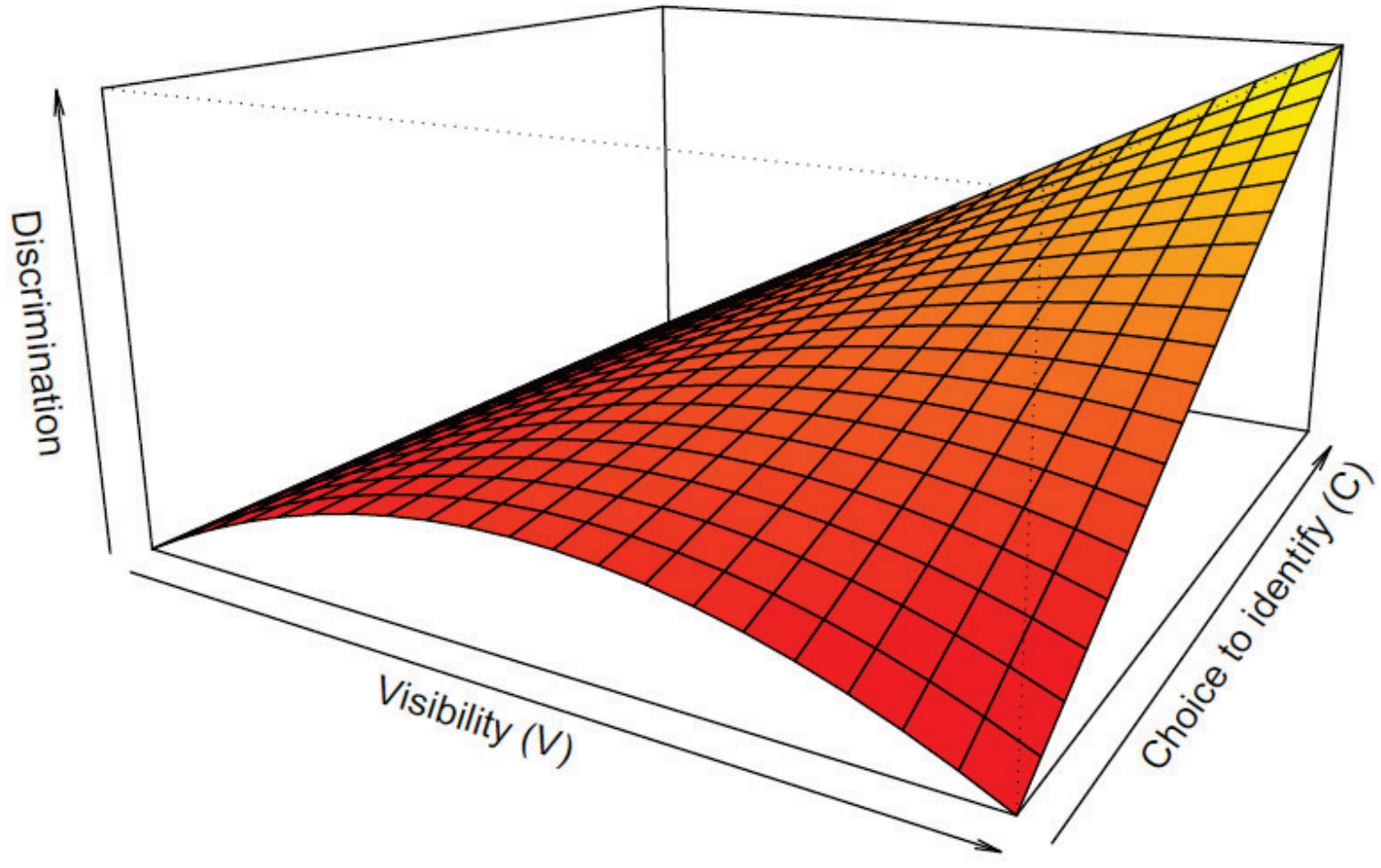

Ideally one would like to directly test some of the hypothesis generated above, but sadly, no data are currently collected with which to directly test all or indeed any of the above hypotheses. While it is clearly difficult to design a reliable proxy for visibility of ethnicity in large surveys, if we are interested in exposure and the number of discriminatory events or situations over a period, one would need counts of those events. Notwithstanding the limitations of using existing survey instruments to measure such phenomenon, one omnibus survey asks about the experience of various forms of discrimination and other possible effects on Indigenous Australians, the 2008 NATSISS. 


\section{Data}

The 2008 NATSISS has information on a range of topics designed by and for the Indigenous population for a large nationally representative sample across all ages. It is an omnibus social survey of Indigenous Australians, covering 13,307 persons with around 7,823 respondents aged 15 years and over alongside 5,484 respondents aged 0-14 years. Data for the NATSISS was collected using face-to-face interviews, with enumeration taking place between August 2008 and April 2009. The survey was conducted in remote and non-remote areas in all Australian States and Territories, collecting information on various topics including language and culture, social networks and support, health, education, housing, labour force status, and financial stress, and crucially for this paper, the reporting of an instance of discrimination in the previous 12 months and the type of discrimination experienced.

In the first part of the sample (the community-sample), a random selection of a number of Indigenous communities and outstations was made; and within these selected communities and outstations a random sample of dwellings was selected. Only Indigenous persons who were usual residents of private dwellings were included in the survey. In non-community areas, dwellings were selected using a stratified multistage sample based on information at the mesh block level within Census Collection Districts. Within each household, a random sub-sample of usual residents of one or two adults (aged 15 years or over) and one or two children (aged 0-14 years) were selected for inclusion in the survey. Specifically, for selected households in discrete remote Indigenous communities and outstations, one Indigenous adult and one Indigenous child were selected and interviewed, whereas in non-remote and remote non-community areas up to two Indigenous adults and up to two Indigenous children per selected household were selected and interviewed. Detailed information was collected for these selected persons, while only a limited number of demographic characteristics are collected on the other members in the households.

\section{Multivariate Analysis of Discrimination}

Clearly there is no existing count data on discrimination against Indigenous Australians, so we adopt the pragmatic option of using statistical models that are appropriate for limited dependent variables that take on the value of 1 or 0 . Logistic regression techniques are used because they provide the odds ratio of summarizing the effect of a particular variable.

To overcome the fact that discriminatory events are measured as a limited dependent variable, a logit transformation is used to ensure that the predicted probabilities, $\mathrm{P}$, lie between zero and one. The basic formulation of the logistic regression model is

$$
\text { Logit } P_{i}=\log \left(\frac{P}{1-P}\right)_{i}=b X_{i}+e_{i}
$$

where $\mathrm{b}$ is a coefficient vector, the explanatory variables $X_{i}$ and $e_{i}$ are the error terms which approximate a normal distribution. See Hosmer and Lemeshow (1989) for fuller discussions. 'Logit P', which is also known as the log odds ratio, is the dependent variable in the logistic regression. The odds ratio are a convenient means of reporting whether the probability is more likely than not. Note that odds ratio of over 1 means that that factor increases the probability of having reported discrimination relative to the probability of not reporting 
discrimination. Conversely, an odds ratio of less than 1 means that a factor is associated with less discrimination. The coefficients in a logistic model must be interpreted as relative to a reference person defined by the omitted categories of the respective groups of explanatory variables.

Biddle et al. (2013) recently published an empirical analysis of both labour market and other discrimination in the previous 12 months using logistic model that can be interpreted in terms of the above theory. This paper builds on the earlier analysis by adding an additional measure of the exposure of Indigenous Australians to non-indigenous people. The basic result to not vary significantly from the underlying controls reported in the earlier article and interested readers are referred to that paper. The following focuses on the new explanatory variable and highlights areas where the results are consistent with the theory described above. Full results can be provided on request.

Local exposure is now measured by the proportion of Indigenous residents in the 2006 Census in each collection district (CD). The geography measure is linked to NATSISS via equivalent information on the remoteness area by state and the decile of the socioeconomic status in the CDs. Two specifications are tested for this variable: a quadratic specification of the Indigenous proportion; and a series of dummy variables for the top and bottom quintile CDs ranked by the proportion of Indigenous residents. Both these specifications allow us to test for non-linearities in exposure.

The labour force variables are also associated with the exposure to risk of discriminatory situations. For example, unemployment and job search are likely to bring the individual into contact with more potential discriminators. Also low status occupations may be less associated with discrimination as these are the jobs that Indigenous people are probably not excluded from.

Perhaps the most sensitive proxy for $\mathrm{E}$ is a measure of the proportion of friends who are Indigenous. If friends accurately reflect social contact in general, then this will captures the extent of social exposure to risk of discrimination. While we do not have a direct measure of $\mathrm{V}$, it is likely that this social variable is a social signal of visibility in terms of willingness to choose as being associated with and as an Indigenous Australian. Hence there is also case that this social capital variable measures $\mathrm{V}$ instead of, or as well as, being a proxy for E.

Other Factors (O) in Biddle et al. (2013) are captured by dummy variables for broad age groups, gender, education, and other characteristics associated with discrimination such as disability status. Also included are variables related to institutions sometimes associated with other common forms of discrimination against Indigenous people such as the criminal justice system and even education (i.e. whether arrested in the previous 5 years or a student). Another reason for including age and education is that they are potentially confounding explanatory factors that are commonly found in any human capital model of labour force status (Stephens 2010). Failure to control for education would limit the ability to interpret the reasons why other factors are associated with discrimination, especially labour market discrimination. 
Mobility or the lack of mobility is another factor that may either be positively or negatively associated with discrimination. Mobility may make it easier to be anonymous and maintain some uncertainty about Indigenous status in the minds of strangers. Alternatively, staying in one area may mean that it allows other local residents and employers to get to know you and your true productivity thus lowering some forms of discrimination. Migration in the previous 5 years is included in the specification to capture such possibilities.

The regression analysis also includes some controls for acculturation to the non-Indigenous society. The proportion who live in households with non-Indigenous people is likely to indicate a reasonably high level of interaction with non-Indigenous society and hence a relatively high E. Accordingly we might expect less reporting of discrimination on the grounds that such people are less of a threat in terms of being less culturally different. However, living with non-Indigenous people may also increase the uncertainty that a person is Indigenous by virtue of observed social relationships and hence $\mathrm{V}$ might be lower than it might otherwise be. Accordingly this variable can be interpreted in terms of $\mathrm{E}$ or $\mathrm{V}$.

One of main issues for analysing the relationship between reported discrimination and labour market outcomes of Indigenous people is that the factors that are associated with the experience of discrimination are also likely to be affected by discrimination (i.e. there is possibly a bi-directional relationship). For example, the experience of arrest puts one in the position to experience more discrimination in the criminal justice system, but the discrimination within that system are widely used to explain the disproportionately high rates of arrest. These high rates of arrest have, in turn, also been argued to have a substantial effect on employment outcomes which can feed into statistical discrimination in the labour market. The following is a descriptive analysis which cannot hope to resolve these endemic problems of joint endogeneity. However, documenting factors associated with the risk of exposure to labour market and non-labour market discrimination will inform future research with a view to understanding these complex relationships underlying discrimination and the effects of discrimination.

The specification for other discrimination is kept similar to that for labour market discrimination to maintain symmetry. Given that adverse interactions with the criminal justice system is one of the major reasons given for reporting non-labour market discrimination, it is theoretically possible that the effect of arrest is even stronger on that form of discrimination than its effect on labour market discrimination because the correlation is direct rather than being mediated through employment and job search experiences.

\subsection{Labour Force Status and the Exposure to Discrimination}

Biddle et al (2013) is replete with findings that underscore the important role of exposure to discrimination, especially with respect to labour force status. As discussed in the introduction unemployed people are significantly more likely to experience labour market discrimination because of reoccurring contact with potential employers (some of whom are potential discriminators), leading them to experience higher rates of labour market discrimination. On the other hand, those not in the labour force are significantly less likely to report labour 
market discrimination; with the odds of experiencing discrimination just $17 \%$ of the odds of those who are employed.

Indigenous people who work in blue collar occupations and in sales are less likely to experience discrimination compared to those in other white collar jobs (such as managers and professionals). This may reflect the ethnic composition of respective professions-white collar workers are more likely to work with a higher proportion of non-Indigenous people (who are the main source of potential discriminators). Prevailing stereotypes that Indigenous work (or should work) in blue collar jobs (Bretherton, Balvin and Kashima 2011) may also lead to increased discrimination against those who disconfirm this stereotype through employment in white collar jobs. It is also consistent with the economic models of discrimination associated with occupational crowding (e.g., Bergmann 1974).

Those who have been employed at the same organisation for more than a year are less likely to experience labour market discrimination. This is not surprising, for if an individual was unhappy in their current job due to the existence of discrimination it is unlikely that they would stay in that job for any substantial period of time. This is also consistent with theory that statistical discrimination will reduce over time as employers get to know the productivity of their workers (that is higher than they originally anticipated).

The underemployed are also more likely to report discrimination. This is not a result of increased exposure in the workplace, but rather may be directly associated with an instance of workplace discrimination. Of course, this may also be a rationalisation of why they have not been able to secure more hours of work when other workers spend longer hours in their jobs.

\subsection{Exposure to Discrimination Revisited}

One of the potentially new measures of exposure in the multivariate analysis for this paper was the proportion of residents in local areas who identify as Indigenous. However, that variable is not significantly associated with discrimination in the basic quadratic specification. When this variable is categorised into quintiles, there is still no significant association with labour market discrimination, however the bottom quintile is associated with significantly higher odds ratio for general discrimination. So where almost everyone else in the area is non-Indigenous the likelihood of reporting non-labour market discrimination is significantly higher (Table 1).

The difference between labour market and other discrimination is probably due to the extensive use of labour force controls that capture the exposure to the risk of discrimination in relation to work. The local exposure to risk of a discriminatory experience is less relevant for labour market discrimination, which is by definition driven more by the nature of jobs in potential workplaces than the local characteristics of an area. Notwithstanding, the likelihood of general discrimination does increase with the exposure to potential discriminators other things being equal. 
Table 1. Logistic Regressions (expressed as odds ratios): Factors Associated with Reporting Employment-related Discrimination or Any Discrimination, 2008

\begin{tabular}{|c|c|c|c|c|}
\hline \multirow{2}{*}{$\begin{array}{l}\text { Explanatory variables } \\
\text { Indigenous proportion of population: lowest quintile }\end{array}$} & \multicolumn{2}{|c|}{$\begin{array}{c}\text { Labour Market } \\
\text { discrimination } \\
\text { Model } 1\end{array}$} & \multicolumn{2}{|c|}{$\begin{array}{c}\text { Any form of } \\
\text { discrimination } \\
\text { Model } 2\end{array}$} \\
\hline & 1.120 & $(0.133)$ & 1.223 & $\overline{(0.092)}$ \\
\hline Indigenous proportion of population: highest quintile & 0.978 & $(0.120)$ & 1.011 & $(0.074)$ \\
\hline Number of observations & 6,838 & & 6,838 & \\
\hline Pseudo R-Squared & 0.112 & & 0.081 & \\
\hline
\end{tabular}

Source: Authors' calculations using the RADL for the 2008 NATSISS.

Notes: The numbers in the brackets give the standard errors for the estimates. The base category for the regression is: Female; aged 35 to 54; Indigenous only household; speaks English at home; did not change usual residence in the previous 5 years; employed full-time as a white collar worker and has been employed in an organisation for more than 12 months; has completed Year 9 or less education; not currently a student; all friends are Indigenous; has not been arrested in the previous 5 years; and does not have a severe or profound disability (i.e. a 'core' disability); lives in an area where the Indigenous proportion of the population is in the middle three quintiles. The pattern of significance for the other explanatory variables also included in Biddle et al (2013) is not reported here because there is no substantial difference to that of the earlier analysis. The average prevalence of labour market and other discrimination in the NATSISS sample is $8 \%$ and $29 \%$ respectively.

\subsection{Social Capital and Visibility of Indigeneity}

One important social capital variable reported in Biddle et al (2013), that arguably indicates the visibility of a person's indigeneity by virtue of observed social relationships, is the proportion of friends who identify as Indigenous (sometimes referred to as 'bonding social capital', see Woolcock 2001). Figure 4 indicates that there is a non-linear relationship between this form of social capital and labour market discrimination. Note that the empirical relationship between other discrimination and bonding social capital is visually indistinguishable from that reported in Figure 4 (so not reported to save space).

Compared to the base category of having all Indigenous friends, people whose friends are mostly Indigenous are significantly more likely to report discrimination while Indigenous people who only have non-Indigenous friends are significantly less likely to experience discrimination. It is possible that those with only non-Indigenous friends have a less salient Indigenous identity (through reduced 'visibility and/or more acculturation) and are thus less at risk of exposure to discrimination while the risk of discrimination may be heightened in social environments with a mix of both Indigenous and non-Indigenous people. This finding could be taken as a confirmation of the theoretical speculations above (i.e., with social visibility increasing as .you move towards the left in Figure 4) 
Figure 4. Labour market discrimination and bonding social capital

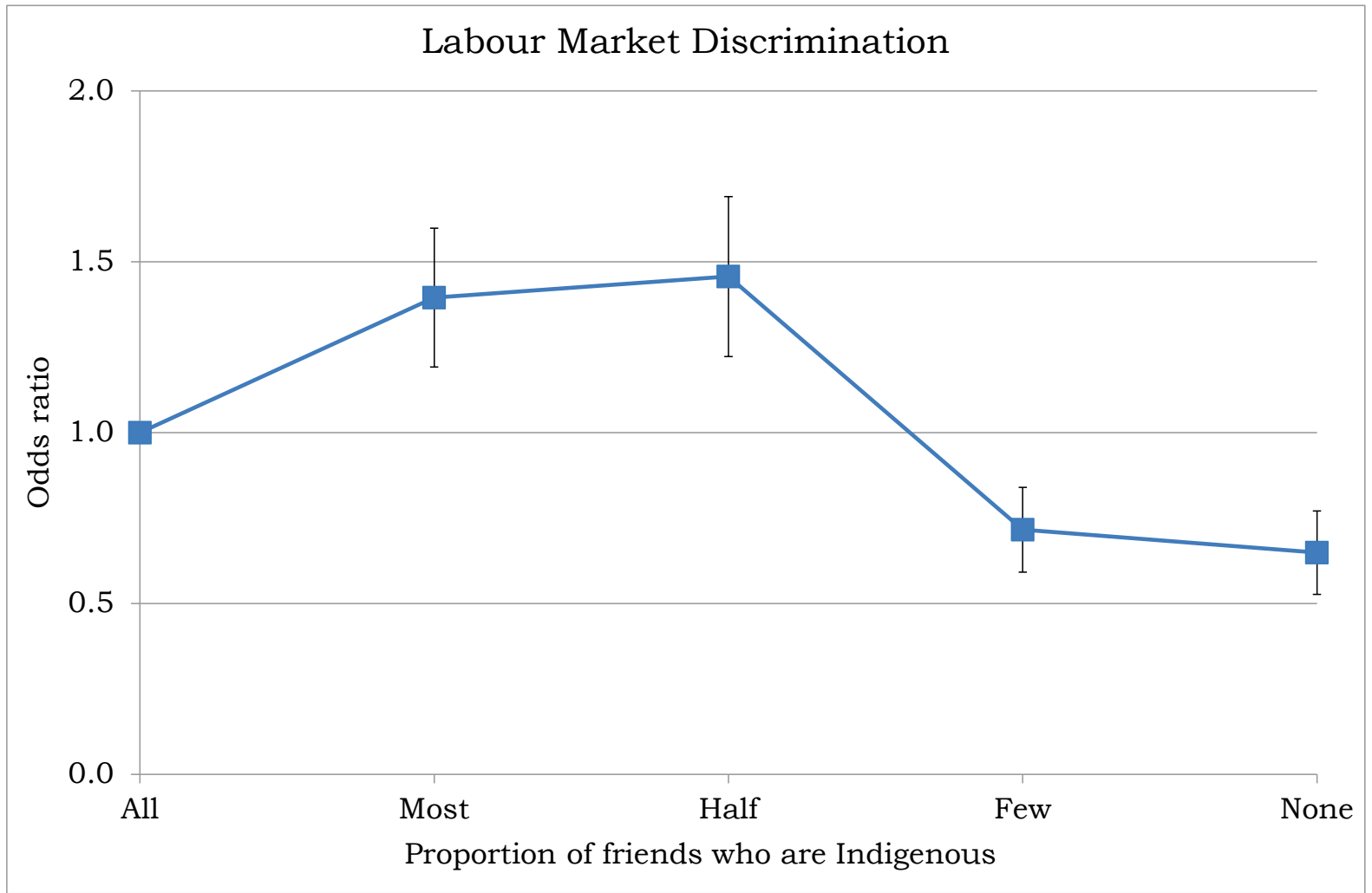

Source: Authors' calculations using the RADL for the 2008 NATSISS.

Notes: See specification listed in the notes to Table 1.

The patterns of odds ratios in Figure 4 is consistent with a choice parameter $\mathrm{C}$ being somewhat less than 0.5 but greater than zero (N.B, C $=0$ is the parameter assumed for Figures 1 and 2). The reason for this is that there is no turning point in discrimination (D) for values of $\mathrm{C}$ over 0.5 and we expect $\mathrm{D}$ to be monotonic in $\mathrm{V}$.

Some might argue that the analysis in this paper does not endogenise the choice to identify, but it rather includes it as a parameter in a model of discrimination (i.e., the expected level of $\mathrm{D}$ conditional on a given level of $\mathrm{V}$ and $\mathrm{C}$ ). Notwithstanding, the theoretical model and empirical analysis point to a level of $\mathrm{C}$ that is informed by an awareness that the more circumstances a person choices to identify the greater the exposure to potential discriminators; this can be thought of as one of the costs of identification). The benefits of identifying as Indigenous Australians are largely defined the social benefits of bonding with people who share a common heritage. There may also be some minor benefits from eligibility to programs or procurement contracts from private or public companies for Indigenous Australians, but these benefits are likely to be small in Australia (cf. the US where Affirmative Action Policies may have conferred considerable benefit to those identifying as a minority ethnic group). Therefore while the choice to publicly identify is not formally modelled, NATSISS respondents are likely to be selecting a parameter value for $\mathrm{C}$ to optimise the costs and benefits of public identification. 


\section{Concluding Remarks}

This paper argues and demonstrates that the processes underlying discrimination can usefully be understood in terms of either the visibility of physical racial characteristics or the social visibility of relationships with people who are publicly identified with a particular ethnic group. Furthermore discriminatory events are the result of the interaction between being identified as a member of that group and the exposure to discriminatory situations involving potential discriminators. The simple theoretical model developed above yields an interesting insight that conventional sources of discrimination can interact with animus-based discrimination in ways that create non-linearities in the reporting of discrimination. That is the most visibly identified people may not be the group that experiences the most discrimination.

Empirical multivariate analysis of labour market and other discrimination confirms that the visibility of a person's Indigenous status and being exposed to potential discriminators are both significant determinants of discrimination and hence are useful concepts for understanding and predicting the existence and reporting of discrimination. Our hypotheses about non-linearities in these determinants appear to be confirmed, or at least are consistent with the data analysed. These non-linearities may be partially driven by the interactions between statistical discrimination and animus-based discrimination (arising from the extent of choice in the decision to identify as Indigenous people) according to our hypothetical simulations. Future research using experimental data should consider the role of animus and choices to identify with certain groups in driving discrimination and combine this with an incorporation of implicit prejudice. Identity is a complex phenomenon to understand, however empirical analysis that uses more refined measures of visibility of group status will be useful in this regard. To the extent that the credibility of visibility measure is improved by external validation, this task may prove difficult for analysis of secondary data (e.g. existing surveys). Psychometric measures of visibility can easily be built in to experimental design. For example, the actors in an audit studies could be ranked for visibility before the study is conducted.

Surveys could theoretically directly ask respondents, what proportion of other people would be able to identify them as a member of the group that may be experiencing discrimination. Alternatively, survey design could also train interviewers to provide an assessment of the extent to which they believe a casual observer would think that the respondent belongs to a particular group using either physical or social cues. There is no necessary expectation generated from our theory as to whether it is important to distinguish between whether the cue for identifying group status was based on physical appearances or social relationshipshowever it is conceivable that different cues may affect various types of discrimination differently. For example the more casual the observer, the greater the reliance on physical appearances as social relationships may only be observed at particular occasions. While our model is not specific to any particular reason for discrimination, the visibility of group status may differ depending on the situations in which potential discriminators observe people who might be identified as being in that group. 
Of course, future research should also consider the possibility that potential discriminators wrongly identify people as being part of the group that is experiencing discrimination. Understanding the mechanisms by which discriminators identify the targets of their discrimination is crucial to constructing the appropriate policy response.

\section{References}

Arrow, K. (1973). Some Models of Racial Discrimination in the Labour Market.. Working Paper 30A, Industrial Relations Section, Woodrow Wilson School, Princeton University, Princeton, NJ.

Arrow, K. (1998). What has economics to say about racial discrimination. Journal of Economic Perspectives, 12(2): 91-100.

Banerjee, R. (2008). An Examination of Factors Affecting Perception of Workplace Discrimination. Journal of Labor Research, 29(4): 380-401.

Becker, G. S. (1971). The Economics of Discrimination. University of Chicago Press, Chicago.

Bergmann, B.R. (1974). Occupational Segregation, Wages and Profits when Employers Discriminate by Race or Sex. Eastern Economic Journal, 1(2): 103-110.

Biddle, N., M. Howlett, B. Hunter and Y. Paradies (2013). Labour Market and other Discrimination facing Indigenous Australians. Australian Journal of Labour Economics, 16(1): 91-113.

Borland, J. and B. Hunter (2000). Does crime affect employment status? - the case of Indigenous Australians. Economica 67(1): 123-144.

Bretherton, D., N. Balvin and Y. Kashima (2011). Hidden Obstacles to Reconciliation in Australia: The Persistence of Stereotypes. Peace Psychology in Australia, Springer US: 197219.

Corrigan, P.W., S.A. Kuwabara and J. O'Shaughnessy ( 2009). The Public Stigma of Mental Illness and Drug Addiction: Findings from a Random Stratified Sample. Journal of Social Work, 9(2): 139-147.

Crocker, J. and B. Major (1989). Social stigma and self-esteem - the self-protective properties of stigma. Psychological Review, 96(4): 608-630.

Crosby, F. (1984). 'The denial of personal discrimination', American Behavioral Scientist 27(3): 371-386.

De Plevitz, R.L. (2000). The failure of Australian legislation on indirect discrimination to detect the systemic racism which prevents Aboriginal people from fully participating in the workforce, Phd thesis, Queensland University of Technology, Brisbane. 
Dion, K.L. (1989). Ethnicity and perceived discrimination: A comparative survey of six ethnic groups of Toronto. 10th Biennial Conference of the Canadian Ethnic Studies Association, Calgary, Alberta, Canada.

Dion, K.L. and K. Kawakami (1996). Ethnicity and perceived discrimination in Toronto: Another look at the personal/group discrimination discrepancy, Canadian Journal of Behavioural Science, 28(3): 203-213.

Galster, G.C. and M. Keeney (1988). Race, Residence, Discrimination and Economic Opportunity: Modelling the Nexus of Urban Racial Phenomena. Urban Affairs Review, 24: 87-117.

Gneezy, U., J. List and M.K. Price (2012). Toward An Understanding of Why People Discriminate: Evidence From a Series of Natural Field Experiments. NBER Working Paper 17855, NBER, Massachusetts http://www.nber.org/papers/w17855.

Goldsmith, A.H., S. Sedo, W. Darity and D. Hamilton (2004). The labor supply consequences of perceptions of employer discrimination during search and on-the-job: Integrating neoclassical theory and cognitive dissonance. Journal of Economic Psychology, 25(1): 1539.

Gould, S.J. (1981). The Mismeasure of Man, Penguin, London, UK.

Greenberg, M.S. and D.M. Frisch (1972). Effect of Intentionality on Willingness to Reciprocate a Favor. Journal of Experimental Social Psychology, 8(2): 99-111.

Guimond, É. (1999). Ethnic mobility and the demographic growth of Canada's aboriginal populations from 1986 to 1996, cat. no. 91-209-XPE, Statistics Canada, Ottawa.

Haider-Markel, D.P. and M.R. Joslyn (2008). Beliefs About the Origins of Homosexuality and Support for Gay Rights: An Empirical Test of Attribution Theory. Public Opinions Quarterly, 75(2): 291-310.

Heider, F. (1958). The Psychology of Interpersonal Relations, Wiley, New York.

Hosmer, D. and Lemeshow, S. (1989). Applied Logistic Regression, John Wiley \& Sons, New York.

Hunter, B. and A. Daly (2013). The Labour Supply of Indigenous Australian Women: the effects of children and interactions with the justice system. Journal of Population Research, 30: $1-18$.

Hunter, B. and M. Gray (2012). 'Indigenous Labour Supply following a Period of Strong Economic Growth', Australian Journal of Labour Economics, 15(2): 141-59.

Hunter, B.H. and M.H. Dungey (2006). Creating a sense of 'CLOSURE': Providing confidence intervals on some recent estimates of indigenous populations. Canadian Studies in Population, 33(1): 1-23. 
McMillan, D.W. and D.M. Chavis (1986). Sense of community: A definition and theory. American Journal of Community Psychology, 14(1): 6-23.

Paradies, Y.C. and J. Cunningham (2009). The DRUID study: racism and self-assessed health status in an indigenous population. Ethnic and Racial Studies, 32(3): 548-573.

Phelps, E.S. (1972). The Statistical Theory of Racism and Sexism. The American Economic Review, 62(4): 659-661.

Quine, W.V. (1981). Theories and Things, Harvard University Press, Cambridge.

Ross, K. (1999). Occasional Paper: Population Issues, Indigenous Australians. cat. no. 4708.0, Australian Bureau of Statistics, Canberra, Australia.

Rukavina, P.B. and W. Li (2011). Adolescents' Perceptions of Controllability and its Relationship to Explicit Obesity Bias. Journal of School Health, 81(1): 8-14.

Stephens, B. (2010). The Determinants of labour force status among Indigenous Australians. Australian Journal of Labour Economics, 13(3): 287-312.

Weiner, B., R.P. Perry and J. Magnusson (1988). An Attributional Analysis of Reactions to Stigmas. Journal of Personality and Social Psychology, 55(5): 738-748.

Woolcock, M. (2001). The Place of Social Capital in Understanding Social and Economic Outcomes. ISUMA: Canadian Journal of Policy Research, 2(1): 11-17. 